\title{
Genetic analysis of clinical mastitis and somatic cell count traits in Austrian Fleckvieh cows
}

\author{
A. Koeck, ${ }^{\star 1}$ B. Heringstad,† C. Egger-Danner,‡ C. Fuerst,‡ P. Winter,§ and B. Fuerst-Walt| ${ }^{\star}$ \\ *Division of Livestock Sciences, Department of Sustainable Agricultural Systems, University of Natural Resources and Life Sciences, \\ Gregor-Mendel-Str. 33, 1180 Vienna, Austria \\ †Department of Animal and Aquacultural Sciences, Norwegian University of Life Sciences, PO Box 5003, N-1432 Ås, Norway \\ ¥ZuchtData EDV-Dienstleistungen GmbH, Dresdner Str. 89/19, 1200 Vienna, Austria \\ §Data, Statistics and Risk Assessment, Austrian Agency for Health and Food Safety, Robert Koch Gasse 17, 2340 Mödling, Austria
}

\begin{abstract}
The objectives of this study were to investigate genetic associations between clinical mastitis (CM) and different somatic cell count traits, and to examine their relationships, in terms of estimated breeding values, with other traits that are routinely evaluated in Austrian Fleckvieh dual-purpose cows. Records on veterinary treatments of CM were available from the Austrian health-monitoring project. For CM, 3 intervals in early lactation were considered: -10 to $50 \mathrm{~d}, 51$ to $150 \mathrm{~d}$, and -10 to $150 \mathrm{~d}$ after calving. Within each interval, absence or presence of CM was scored as 1 or 0 based on whether or not the cow had recorded at least one veterinary treatment of $\mathrm{CM}$. The average somatic cell score of the first 2 test-days after calving was defined as early lactation average somatic cell score, and lactation mean somatic cell score was the average of all test-day somatic cell scores from 8 to 305 d after calving. Subclinical mastitis was expressed as a binary trait based on prolonged elevated somatic cell counts. If somatic cell counts on 3 consecutive test-days in the interval from 8 to 305 d after calving were above 200,000 cells/ $\mathrm{mL}$, the binary variable subclinical mastitis was defined as 1 and otherwise 0. Records of Austrian Fleckvieh cows, with calving from January 1, 2007, to February 28, 2009, were analyzed using univariate and bivariate sire models. Threshold liability models were applied for binary traits, and Gaussian models were used for early lactation average somatic cell score and lactation mean somatic cell score. A Bayesian approach using Gibbs sampling was applied for genetic analyses. Posterior means of heritability of liability to $\mathrm{CM}$ were 0.06 and 0.02 in the first and second interval, respectively, and 0.05 in the full period ( -10 to $150 \mathrm{~d}$ ). Heritability estimates of somatic cell count traits were higher (0.09 to 0.13$)$. The posterior mean of the genetic correlation
\end{abstract}

Received May 19, 2010.

Accepted August 12, 2010.

${ }^{1}$ Corresponding author: astrid.koeck@boku.ac.at between $\mathrm{CM}$ in lactation period 1 ( -10 to $50 \mathrm{~d}$ after calving) and 2 (51 to $150 \mathrm{~d}$ after calving) was close to unity. Posterior means of genetic correlations between $\mathrm{CM}$ and somatic cell count traits ranged from 0.64 to 0.77. Because CM and somatic cell count describe different aspects of udder health, information on both traits should be considered for selection of bulls. Correlations of sire breeding values revealed that especially the udder conformation trait udder depth may be useful as additional information to reduce both $\mathrm{CM}$ and somatic cell count.

Key words: clinical mastitis, somatic cell count, genetic correlation, dairy cattle

\section{INTRODUCTION}

Breeding for mastitis resistance is becoming increasingly important because of its effect on farm economy and animal welfare and because consumer demands for healthy and naturally produced products are increasing. Furthermore, the unfavorable genetic correlations between milk production and clinical mastitis (CM) are well known (Heringstad et al., 2000).

Most of the countries that perform genetic evaluations for mastitis resistance lack records of CM because disease recording systems are not well developed. Thus, most commonly SCC is used as an indirect measure. In Austria, genetic evaluations for udder health are based on SCC and have been carried out since 1998. At present a fixed regression test-day model is used for routine genetic evaluation. Somatic cell count is included in the total merit index, currently with a relative weight of 9.7\% for Fleckvieh cattle (Fuerst et al., 2010).

In a review, Heringstad et al. (2000) reported that estimates of genetic correlations between CM and SCC ranged from 0.3 to 0.8 , with an average of 0.6 based on Nordic field data, which indicates that SCC and CM cannot be considered as the expression of the same trait. High SCC reflects more subclinical and chronic cases of mastitis, which are infrequently recorded in the usual performance testing schemes. Detecting clinical events 
with rapid recovery on the basis of monthly test-day SCC is usually not possible. Shook and Schutz (1994) pointed out that the monthly sampling scheme for SCC will detect perhaps 10 to $20 \%$ of these infections. Furthermore, cows that undergo antibiotic treatment on the day of herd testing are usually not sampled for milk analysis, and high SCC peaks will not be recorded. In contrast, the trait $\mathrm{CM}$ ignores subclinical cases of mastitis. As shown by Carlén et al. (2004), selection will be most efficient when information on $\mathrm{CM}$ and SCC are combined.

Previous studies also indicate that genetic correlations between CM in different parts of lactation, at least in early and late lactation, are much lower than one. This implies that mastitis cannot be regarded as the same trait throughout lactation (Heringstad et al., 2004; Negussie et al., 2006; Zwald et al., 2006).

Until now, genetic evaluations of $\mathrm{CM}$ have been carried out only in the Nordic countries where health traits have been routinely and widely recorded for more than 30 years. In Austria in 2006, a project to establish a nationwide health-monitoring system for cattle was started, in which diagnoses from veterinarians are recorded (Egger-Danner et al., 2007).

The objectives of this study were to use CM records from the Austrian health-monitoring project to 1) infer heritabilities and genetic correlations of CM in different stages of lactation; 2) estimate genetic correlations between CM, early lactation SCS (ESCS), lactation mean SCS (LSCS), and subclinical mastitis derived from SCC test-day records (SM); and 3) examine relationships between breeding values for $\mathrm{CM}$ and $\mathrm{SCC}$ traits and other traits that are routinely evaluated for Austrian Fleckvieh cows. A Bayesian approach using Gibbs sampling was applied for the genetic analyses.

\section{MATERIALS AND METHODS}

\section{Data}

Mastitis data from Fleckvieh cows were obtained from the Austrian project "Health Monitoring in Cattle," in which diagnoses from veterinarians are recorded (Egger-Danner et al., 2007). Recording of health data on farms is currently voluntary. To ensure that all cows were from herds actively participating in the healthrecording system, only herds with at least one recorded diagnosis (any disease) per 10 cows and year were considered. Furthermore, only data from veterinarians who recorded at least 500 diagnoses distributed over the whole period were considered in this analysis to rule out inconsistent data collection. About $25 \%$ of the farms were excluded by this data editing.
Table 1. First incidence (\%) of acute and chronic mastitis by stage of lactation, measured as days after calving, for cows that completed 305 d after calving

\begin{tabular}{lcc}
\hline $\begin{array}{l}\text { Days from } \\
\text { calving }\end{array}$ & $\begin{array}{c}\text { Acute mastitis } \\
(\mathrm{n}=2,562)\end{array}$ & $\begin{array}{c}\text { Chronic mastitis } \\
(\mathrm{n}=1,668)\end{array}$ \\
\hline-10 to 0 & 6.4 & 3.2 \\
1 to 10 & 17.1 & 8.0 \\
11 to 30 & 12.2 & 7.9 \\
31 to 60 & 12.4 & 8.0 \\
61 to 90 & 10.2 & 6.4 \\
91 to 120 & 8.2 & 5.0 \\
121 to 150 & 7.9 & 5.2 \\
151 to 180 & 6.6 & 4.7 \\
181 to 210 & 4.9 & 4.0 \\
211 to 240 & 4.6 & 4.0 \\
241 to 270 & 4.3 & 10.8 \\
271 to 305 & 5.2 & 32.8 \\
\hline
\end{tabular}

Records from the first 5 lactations of Austrian Fleckvieh cows calving between January 1, 2007, and February 28, 2009, were included in this study. Age at first calving was between 19 and $43 \mathrm{mo}$, and records of animals with a calving interval shorter than $300 \mathrm{~d}$ or longer than $800 \mathrm{~d}$ were excluded.

The trait CM included veterinary treatments of acute and chronic mastitis. Cows with acute mastitis have high SCC and exhibit clinical signs of illness, whereas chronic-mastitis-affected cows have persistently increased SCC. Analyzing CM throughout the entire lactation was impossible. As shown in Table 1, the majority of acute CM treatments occurred in early lactation, whereas most cases of chronic mastitis were at the end of lactation. The latter may imply that veterinarians partly coded cows receiving dry cow therapy as chronic cases. Therefore, a new code for dry cow therapy was introduced in October 2008. In the future it should thus be possible to analyze $\mathrm{CM}$ in late lactation.

In this study CM only in the early part of lactation (to $150 \mathrm{~d}$ after calving) was analyzed. Clinical mastitis was defined as a binary trait ( 1 or 0 ) based on whether or not the cow had at least one veterinary treatment of CM recorded within each of the 3 intervals: from -10 to $50 \mathrm{~d}$ after calving (CM1), from 51 to $150 \mathrm{~d}$ after calving (CM2), and from -10 to $150 \mathrm{~d}$ after calving (CM3). All cows culled due to udder problems within the defined time period were considered as diseased even if they did not have a record of veterinary treatment. Cows culled because of other reasons were considered as healthy if they had no CM treatment.

Test-day records of SCC were taken at 5-wk intervals following an alternate a.m.-p.m. recording scheme. Three SCC traits were defined as mastitis indicators for genetic evaluation. To achieve an approximately normal distribution, SCC was transformed to SCS as follows: $\mathrm{SCS}=\log _{2}(\mathrm{SCC} / 100,000)+3$. Early lactation 
Table 2. Summary statistics of the data set

\begin{tabular}{lccc}
\hline Trait & $\begin{array}{c}\text { Days from } \\
\text { calving }\end{array}$ & $\begin{array}{c}\text { Records, } \\
\mathrm{n}\end{array}$ & Mean \\
\hline CM1, ${ }^{1} \%$ & -10 to 50 & 33,855 & 5.6 \\
CM2, ${ }^{1} \%$ & 51 to 150 & 24,398 & 4.9 \\
CM3 ${ }^{1} \%$ & -10 to 150 & 26,273 & 9.6 \\
ESCS $^{2}$ & & 38,818 & 1.9 \\
LSCS $^{3}$ & & 27,042 & 2.4 \\
SM, $^{4} \%$ & & 27,042 & 13.0 \\
\hline
\end{tabular}

${ }^{1}$ Percentage of cows with at least one record of veterinary treatment of clinical mastitis $(\mathrm{CM})$ or culled due to udder problems in the defined period.

${ }^{2}$ Early lactation SCS; average SCS of test-day 1 and 2 after calving in the interval from 8 to $100 \mathrm{~d}$ after calving.

${ }^{3}$ Lactation mean SCS; average SCS of at least 6 test-days in the interval from 8 to $305 \mathrm{~d}$ after calving.

${ }^{4}$ Subclinical mastitis; percentage of cows with at least 3 consecutive test-days $>200,000$ cells $/ \mathrm{mL}$ in the interval from 8 to $305 \mathrm{~d}$ after calving. At least 6 test-days were required for inclusion.

SCS was calculated as the average SCS of the first 2 test-days in the interval from 8 to $100 \mathrm{~d}$ after calving, when cows are at high risk of contracting mastitis. Lactation mean SCS was defined as the average of all test-day SCS in the interval from 8 to $305 \mathrm{~d}$ after calving. At least 6 test-day SCC records were required for the calculation of LSCS. Subclinical mastitis can be identified by increased SCC and is usually of long duration. An SCC threshold of exceeding 200,000 cells/mL is generally considered to be evidence of SM (Schukken et al., 2003). Therefore, SM was expressed as a binary trait based on prolonged elevated SCC. If SCC on 3 consecutive test-days in the interval from 8 to $305 \mathrm{~d}$ after calving were higher than 200,000 cells/mL, the binary variable was scored as 1 , and it was scored as 0 otherwise. Only cows with at least 6 SCC test-day records were considered for this trait.

All data sets were further restricted separately to include only sires with at least 30 daughters and herd classes with at least 10 calving cows. After edits, the final data set included a total of 43,299 records of 26,748 Fleckvieh cows from 1,658 herds. However, not all animals had information on all traits. Summary statistics of the analyzed traits are given in Table 2 . The proportion of first-, second-, third-, fourth-, and fifth-lactation records was approximately $30,25,20,15$, and $10 \%$, respectively. The mean frequencies of CM1, CM2, and CM3 were 5.6, 4.9, and 9.6\%, respectively. The mean ESCS and LSCS were 1.9 and 2.4, respectively. For $\mathrm{SM}$, a mean frequency of $13 \%$ was calculated, which is rather low. However, Fleckvieh is also the breed with the lowest average SCC $(194,167$ cells/mL) in Austria (ZuchtData, 2009).

The sire pedigree file had information on sires and maternal grandsires of the 223 bulls with daughters in the data set, tracing back 7 generations. The resulting pedigree file contained the relationship of 917 males.

\section{Statistical Models}

For genetic analyses, a Bayesian approach using Gibbs sampling (e.g., Sorensen and Gianola, 2002) was applied. Univariate and bivariate sire models were fitted, with threshold-liability models for the binary traits CM1, CM2, CM3, and SM, and Gaussian models for ESCS and LSCS. The threshold-liability model (e.g., Gianola and Foulley, 1983) accounts for the binary (0, 1) nature of the data. The threshold model assumes the existence of an unobservable, underlying, continuous variable, called liability $(\lambda)$. The observed binary variable takes the value 1 if the liability is larger than a fixed threshold and 0 otherwise. Because the threshold and the residual variance are not identifiable for binary traits, these values are constrained to 0 and 1 , respectively.

Initially, univariate analyses were applied for all traits. Consecutively, 8 bivariate analyses were carried out for the following trait combinations: 1) CM1-CM2, 2) CM1-ESCS, 3) CM1-LSCS, 4) CM1-SM, 5) CM3ESCS, 6) CM3-LSCS, 7) CM3-SM, and 8) SM-LSCS. Other trait combinations were not analyzed because the first analysis revealed a genetic correlation near unity between CM1 and CM2, and therefore only one of them (CM1) was chosen for analyses of genetic correlations to SCS traits. Furthermore, CM1 and CM3 are overlapping traits (CM3 contains CM1) and so are ESCS and LSCS. Genetic correlations were, therefore, not estimated for these 2 pairs of traits.

In matrix notation, the model for CM1, CM2, and CM3 was

$$
\boldsymbol{\lambda}=\mathbf{X} \boldsymbol{\beta}+\mathbf{Z}_{\mathbf{h}} \mathbf{h}+\mathbf{Z}_{\mathbf{s}} \mathbf{s}+\mathbf{e},
$$

where $\boldsymbol{\lambda}$ is a vector of unobserved liabilities to CM1, $\mathrm{CM} 2$, or CM3; $\boldsymbol{\beta}$ is a vector of systematic effects, including effects of age at calving-parity and year-season of calving; $\mathbf{h}$ is a vector of herd of calving effects; $\mathbf{s}$ is a vector of sire effects; $\mathbf{e}$ is a vector of residuals; and $\mathbf{X}$, $\mathbf{Z}_{\mathrm{h}}$, and $\mathbf{Z}_{\mathrm{s}}$ are the corresponding incidence matrices.

Four calving age classes were formed for each of the first 2 parities. Age at first calving was grouped into $<27,27$ to 28,29 to 30 , and $>30 \mathrm{mo}$, and age at second calving was classified into $<40,40$ to 41,42 to 44 , and $>44$ mo. For older cows, age-parity classes were parity 3,4 , and 5 . Year-season of calving had 13 classes, from January 2007 to February 2009, in which seasons were formed by combining 2 mo (January and February, . . .). The permanent environmental effect, which 
Table 3. Means and SD of the posterior distributions of sire, herd, and residual variance and of heritability of liability to clinical mastitis (CM) in lactation intervals 1 ( -10 to $50 \mathrm{~d}$ after calving), 2 (51 to $150 \mathrm{~d}$ after calving), and 3 ( -10 to $150 \mathrm{~d}$ after calving)

\begin{tabular}{|c|c|c|c|c|c|c|}
\hline \multirow[b]{2}{*}{ Item } & \multicolumn{2}{|c|}{ CM1 } & \multicolumn{2}{|c|}{ CM2 } & \multicolumn{2}{|c|}{ CM3 } \\
\hline & Mean & $\mathrm{SD}$ & Mean & $\mathrm{SD}$ & Mean & SD \\
\hline Sire variance & 0.018 & 0.006 & 0.006 & 0.003 & 0.015 & 0.005 \\
\hline Herd variance & 0.141 & 0.015 & 0.138 & 0.019 & 0.168 & 0.015 \\
\hline Residual variance & 1 & 0 & 1 & 0 & 1 & 0 \\
\hline Heritability $^{1}$ & 0.063 & 0.020 & 0.021 & 0.012 & 0.051 & 0.016 \\
\hline
\end{tabular}

${ }^{1}$ Heritability: $h^{2}=4 \sigma_{s}^{2} /\left(\sigma_{s}^{2}+\sigma_{h}^{2}+\sigma_{e}^{2}\right)$, where $\sigma_{s}^{2}=$ sire variance, $\sigma_{h}^{2}=$ herd variance, and $\sigma_{e}^{2}=$ residual variance.

accounts for the correlation between repeated measures on the same cow, was not included in the models for CM because preliminary analyses showed that this effect is negligible so far.

The following model was used for ESCS, LSCS, and liability to SM:

$$
\mathbf{y}=\mathbf{X} \boldsymbol{\beta}+\mathbf{Z}_{\mathbf{h}} \mathbf{h}+\mathbf{Z}_{\mathrm{s}} \mathbf{s}+\mathbf{W} \mathbf{p}+\mathbf{e}
$$

where $\mathbf{y}$ is a vector of observations for ESCS and LSCS or unobserved liabilities to $\mathrm{SM} ; \boldsymbol{\beta}$ is a vector of systematic effects, including effects of age at calving-parity and year-season of calving (as described above); $\mathbf{h}$ is a vector of herd of calving effects; $\mathbf{s}$ is a vector of sire effects; $\mathbf{p}$ is a vector of permanent environmental effects of the cow; $\mathbf{e}$ is a vector of residuals; and $\mathbf{X}, \mathbf{Z}_{\mathbf{h}}, \mathbf{Z}_{\mathrm{s}}$, and $\mathbf{W}$ are the corresponding incidence matrices.

\section{Sampling and Convergence Diagnostics}

Bayesian analyses were run using the RJMC routine implemented in the DMU software (Madsen and Jensen, 2008). The sample size and length of burn-in were decided based on the convergence diagnostics of Raftery and Lewis (1992) and on visual inspections of trace plots using the BOA software package (Smith, 2007). Inference for different traits and trait combinations was based on chain lengths of between 100,000 and 350,000 samples. The burn-in was 5,000 rounds for all analyses.

\section{Genetic Evaluations}

Sire posterior means for CM1, CM2, CM3, ESCS, LSCS, and SM from the Bayesian analyses were reversed in sign. Thus, higher breeding values indicate genetically favorable sires. In accordance with the Austrian routine breeding value estimation, estimated breeding values were standardized to relative breeding values with a mean of 100 and a genetic standard deviation of 12. Pearson correlations between breeding values of CM and SCC traits with official EBV of selected production, fitness, and udder conformation traits were computed, based on sires with at least 50 daughters for $\mathrm{CM}$ and SCC traits.

\section{RESULTS AND DISCUSSION}

\section{Heritability of CM}

Variance components and heritability estimates of liability to CM1, CM2, and CM3 from the univariate analyses are given in Table 3. The posterior means (SD) of heritability of liability were $0.06(0.02)$ and 0.02 (0.01) for CM1 and CM2, respectively, and 0.05 (0.02) for CM3. The posterior distributions of heritability were reasonably sharp and symmetric for all CM traits, as illustrated in Figure 1. Although the distributions for CM1 and CM2 overlap, the Bayesian analysis suggests a higher heritability of CM1. It seems that most of the genetic variation of CM is found in early lactation, when the cows are facing high physiological demands. Furthermore, the slightly lower heritability estimate for the longer period (CM3) compared with CM1 indicates loss of information when pooling the periods CM1 and CM2 together. Our results are in agreement with previous studies by Lund et al. (1999) and Negussie et al. (2006). Lund et al. (1999) found, transformed to the underlying liability scale, the highest heritability in early lactation (from -10 to $50 \mathrm{~d}$ after calving, $\mathrm{h}^{2}=0.12$ ), whereas in the period from 50 to $180 \mathrm{~d}$ after calving, the estimate was much lower $\left(h^{2}=0.002\right)$. Negussie et al. (2006) reported heritabilities of 0.08 and 0.04 in the intervals -30 to $30 \mathrm{~d}$ after calving and 31 to $150 \mathrm{~d}$ after calving, respectively, in first-lactation Finnish Ayrshire cows. In both mentioned studies, a slightly lower heritability was observed for the full period compared with the first period under investigation. In first-lactation Norwegian Red cows, Heringstad et al. (2004) found a heritability of 0.09 in the first period ( $-30 \mathrm{~d}$ to calving) and only a slight drop in subsequent periods, with heritabilities between 0.06 and 0.07. In contrast, Zwald et al. (2006) 


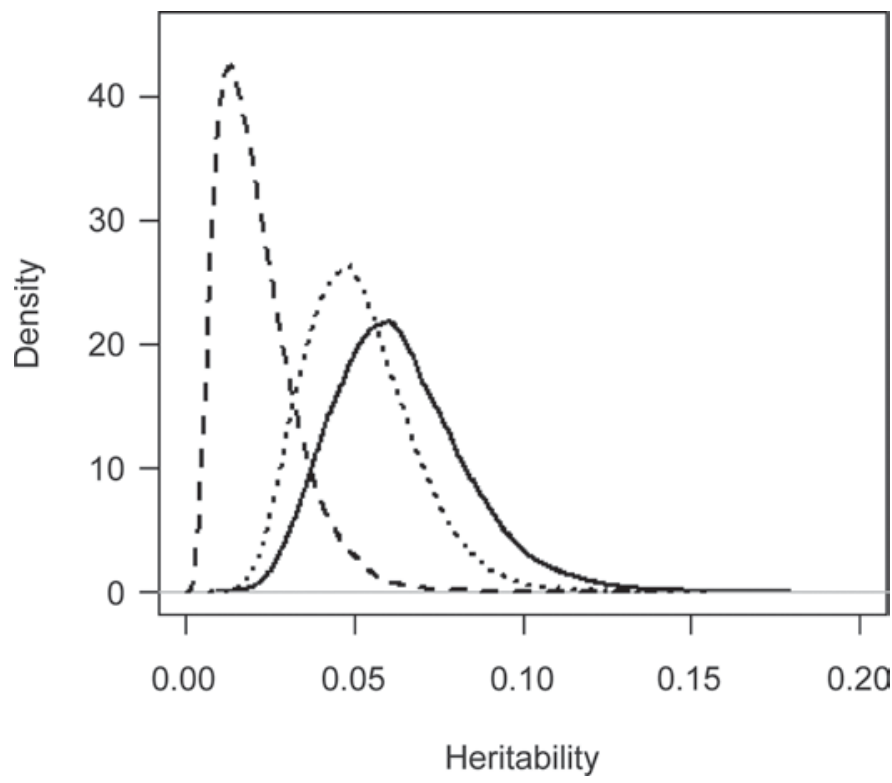

Figure 1. Posterior distributions of heritability $\left[h^{2}=4 \sigma_{s}^{2} /\left(\sigma_{s}^{2}+\sigma_{h}^{2}+\sigma_{e}^{2}\right)\right]$ of liability to clinical mastitis in lactation intervals 1 ( -10 to $50 \mathrm{~d}$ after calving, solid line), 2 (51 to $150 \mathrm{~d}$ after calving, dashed line), and 3 ( -10 to $150 \mathrm{~d}$ after calving, dotted line). $\sigma_{s}^{2}=$ sire variance, $\sigma_{h}^{2}=$ herd variance, $\sigma_{e}^{2}=$ residual variance.

observed a trend toward increasing heritability estimates as lactations progressed in US Holstein cows.

\section{Heritability of SCC Traits}

Estimated variance components and heritabilities for ESCS and LSCS and of liability to SM from the univariate analyses are given in Table 4 . The posterior means (SD) of heritability were 0.09 (0.02), 0.13 (0.02), and 0.10 (0.02) for ESCS, LSCS, and SM, respectively. As shown in Figure 2, the posterior distributions of heritability were sharp and symmetric for all traits. The distributions of ESCS and LSCS overlap, but it seems that heritability of ESCS is lower than heritability of LSCS. This was expected because the latter involves an average of more SCS records. Posterior mean estimates

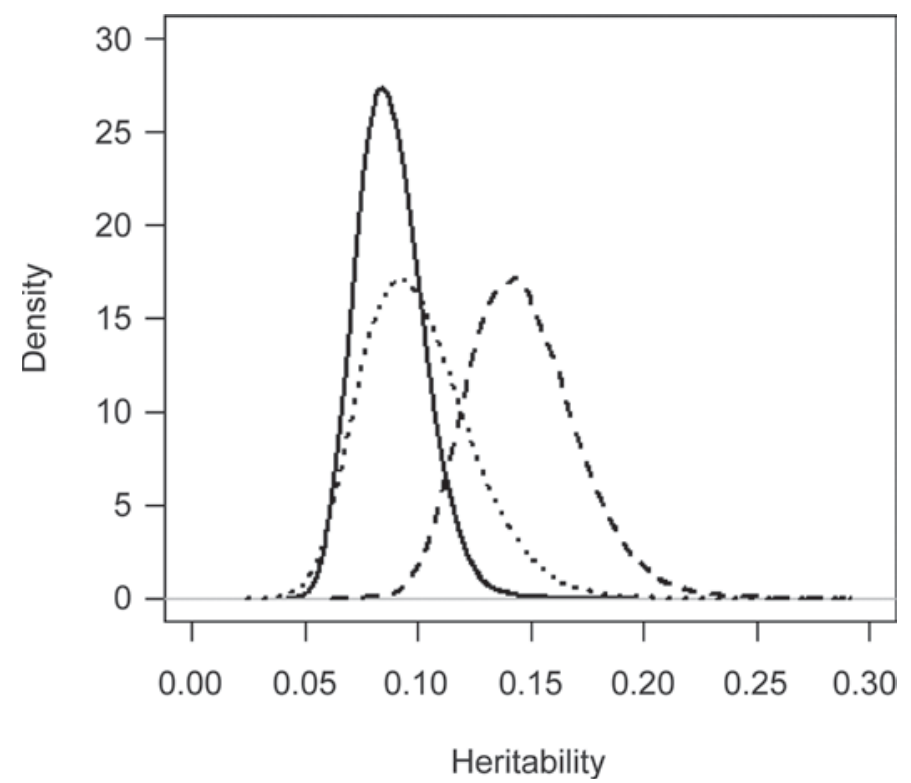

Figure 2. Posterior distributions of heritability $\left[h^{2}=4 \sigma_{s}^{2} /\left(\sigma_{s}^{2}+\sigma_{h}^{2}+\sigma_{p e}^{2}+\sigma_{e}^{2}\right)\right]$ of early lactation SCS (solid line), lactation mean SCS (dashed line), and liability to subclinical mastitis (dotted line). $\sigma_{s}^{2}=$ sire variance, $\sigma_{h}^{2}=$ herd variance, $\sigma_{p e}^{2}=$ permanent environmental variance, $\sigma_{e}^{2}=$ residual variance.

of heritability for ESCS and LSCS agree with previous studies (Carlén et al., 2004; Heringstad et al., 2006). For SM derived from SCC, with a threshold of 200,000 cell/mL, Svendsen and Heringstad (2006) reported heritabilities on the observable scale of $0.045,0.049$, and 0.051 for first-, second-, and third-lactation Norwegian Red cows, respectively.

\section{Correlations Between CM1 and CM2}

Table 5 shows posterior means and standard deviations of the genetic, herd, and residual correlations between liabilities to CM1 and CM2. The posterior means of the genetic and herd correlation between the 2 traits were near unity, whereas the posterior mean of the residual correlation was close to zero (0.06). This

Table 4. Means and SD of the posterior distributions of sire, herd, permanent environmental, and residual variance and of heritability of early lactation SCS (ESCS), lactation mean SCS (LSCS), and liability to subclinical mastitis (SM)

\begin{tabular}{|c|c|c|c|c|c|c|}
\hline \multirow[b]{2}{*}{ Item } & \multicolumn{2}{|c|}{ ESCS } & \multicolumn{2}{|c|}{ LSCS } & \multicolumn{2}{|c|}{ SM } \\
\hline & Mean & $\mathrm{SD}$ & Mean & $\mathrm{SD}$ & Mean & $\mathrm{SD}$ \\
\hline Permanent environmental variance & 0.509 & 0.018 & 0.500 & 0.012 & 0.914 & 0.087 \\
\hline Residual variance & 1.534 & 0.017 & 0.617 & 0.010 & 1 & 0 \\
\hline Heritability $^{1}$ & 0.088 & 0.015 & 0.127 & 0.021 & 0.100 & 0.024 \\
\hline
\end{tabular}

${ }^{1}$ Heritability: $h^{2}=4 \sigma_{s}^{2} /\left(\sigma_{s}^{2}+\sigma_{h}^{2}+\sigma_{p e}^{2}+\sigma_{e}^{2}\right)$, where $\sigma_{s}^{2}=$ sire variance, $\sigma_{h}^{2}=$ herd variance, $\sigma_{p e}^{2}=$ permanent environmental variance, and $\sigma_{e}^{2}=$ residual variance. 
suggests that CM1 and CM2 are genetically almost the same trait.

The point estimate of genetic correlation between CM in different parts of lactation in our study was higher than the 0.37 to 0.73 range reported by Heringstad et al. (2004) in early lactation for Norwegian Red cows. Zwald et al. (2006) obtained even lower genetic correlations in the range of 0.33 to 0.46 between $\mathrm{CM}$ within 50 $\mathrm{d}$ after calving and CM from 51 to $155 \mathrm{~d}$ after calving in the first 3 lactations of US Holstein cows. Our result, however, was similar to the estimates of Lund et al. (1999) and Negussie et al. (2006). Lund et al. (1999) found a genetic correlation of 0.89 between mastitis in early lactation ( -10 to $50 \mathrm{~d}$ after calving) and in the period 50 to $180 \mathrm{~d}$ after calving for Red Danish. Negussie et al. (2006) obtained a correlation of 0.87 between $\mathrm{CM}$ in the interval -30 to $30 \mathrm{~d}$ after calving and 31 to 150 d after calving for Finnish Ayrshire cows.

\section{Correlations Between CM and SCC Traits}

The posterior means and standard deviations of the genetic, herd, and residual correlations of CM1 or CM3 with ESCS, LSCS, and SM are given in Table 5. As illustrated in Figure 3, the posterior distributions of the genetic correlations among CM1 and SCS traits were reasonably symmetric, and all posterior distributions showed a considerable overlap. The posterior standard deviations were quite high, so the genetic correlations should be interpreted with caution. Similar results were obtained among CM3 and SCS traits.

Posterior means of the genetic correlations between CM1 and ESCS and between CM3 and ESCS were 0.77 and 0.76 , respectively, with a standard deviation of 0.10. The results indicate that, although CM1 or CM3 and ESCS have some common genetic background, they are not the same trait. Heringstad et al. (2006) found a genetic correlation of 0.62 between CM and SCS in early first lactation in Norwegian Red cows.

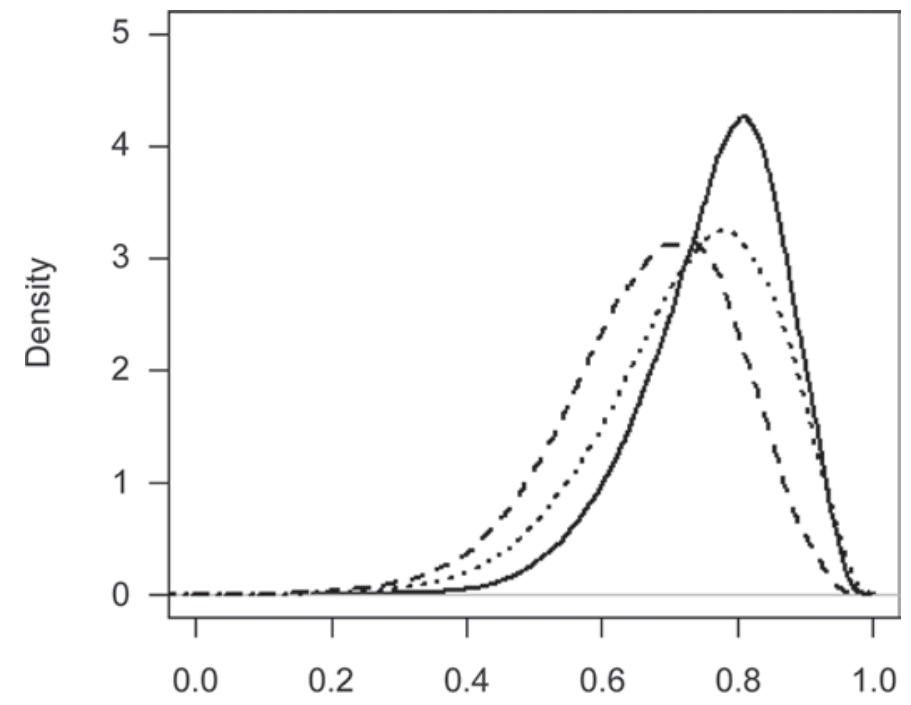

Genetic correlation

Figure 3. Posterior distributions of genetic correlations between liability to clinical mastitis in lactation interval 1 ( -10 to $50 \mathrm{~d}$ after calving) and early lactation SCS (solid line), lactation mean SCS (dashed line), and liability to subclinical mastitis (dotted line).

The posterior means (SD) of genetic correlations of CM1 or CM3 with LSCS were $0.67(0.13)$ and 0.64 (0.13), respectively, which despite slightly different trait definitions are in agreement with previous studies. Rupp and Boichard (1999) reported a genetic correlation of 0.72 between CM and SCS within $180 \mathrm{~d}$ after calving. Carlén et al. (2004) obtained genetic correlations between CM and SCS within $150 \mathrm{~d}$ after calving of $0.68,0.66$, and 0.77 for first-, second-, and thirdlactation Swedish Holstein. In Norwegian Red cows, Ødegård et al. (2004) found a lower correlation of 0.53 between CM and LSCS.

In our study, ESCS tended to show a stronger genetic correlation to CM traits than did LSCS. This was expected because ESCS and CM1, and CM3 to a large

Table 5. Posterior means and SD of genetic, herd, permanent environmental, and residual correlations among clinical mastitis (CM) in lactation intervals 1 ( -10 to $50 \mathrm{~d}$ after calving), 2 (51 to $150 \mathrm{~d}$ after calving), and 3 ( -10 to $150 \mathrm{~d}$ after calving), early lactation SCS (ESCS), lactation mean SCS (LSCS), and subclinical mastitis (SM)

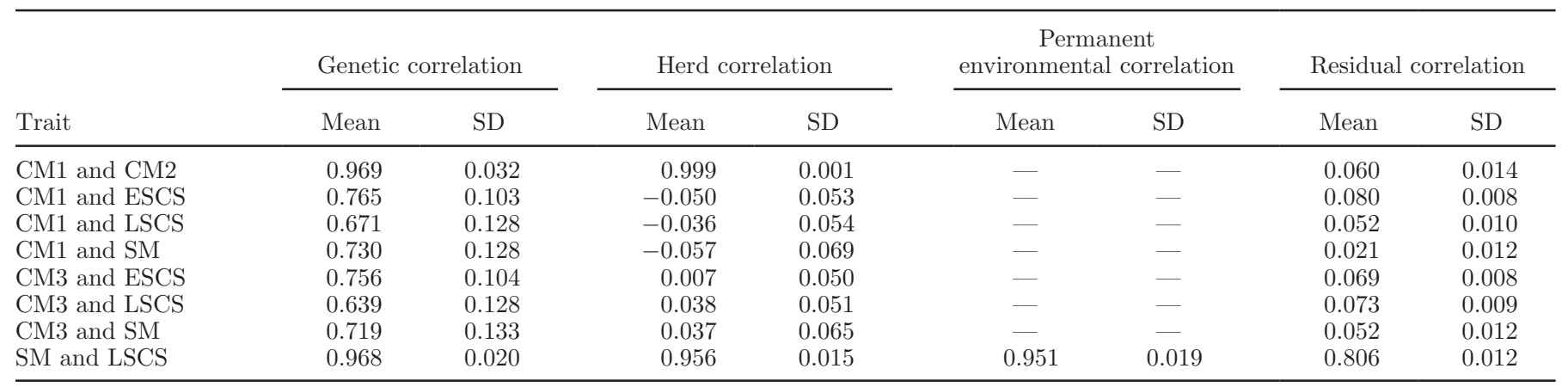


extent, covered the same time period. Negussie et al. (2008) reported that genetic correlations between CM in early lactation (from -7 to $30 \mathrm{~d}$ after calving) and test-day SCS varied from 0.41 to 0.77 , with the greatest genetic correlation in the early part of lactation. Genetic correlations between CM in late lactation (31 to $300 \mathrm{~d}$ after calving) and test-day SCS ranged from 0.34 to 0.71 , with the greatest correlations in the late stages of lactation. This indicates that CM and SCS from the same interval may have a more similar genetic basis.

Posterior means (SD) of genetic correlations of CM1 and CM3 with SM were 0.73 (0.13) and 0.72 (0.13), respectively. In first-lactation Norwegian Red cows, Svendsen and Heringstad (2006) found a much lower genetic correlation of 0.35 between SM derived from SCC with a threshold of 200,000 cell $/ \mathrm{mL}$ and CM in early lactation ( -15 to $30 \mathrm{~d}$ after calving), whereas a stronger correlation of 0.61 was observed to $\mathrm{CM}$ in later lactation (31 to $120 \mathrm{~d}$ after calving).

The posterior means of herd correlations between the different trait combinations were close to zero (Table 5). This indicates that herds with higher SCC do not have higher susceptibility to CM. The posterior means of the residual correlations were low and ranged from 0.02 to 0.08 .

\section{Correlations Between SM and LSCS}

Posterior means and standard deviations of the genetic, herd, permanent environmental, and residual correlations between SM and LSCS are presented in Table 5 . The posterior means of the genetic, herd, and permanent environmental correlation were close to 1 , whereas the posterior mean of the residual correlation was slightly lower (0.81). This result suggests that SM and LSCS are almost the same trait. Other studies dealing with these traits were not found in the literature.

\section{Associations with Production, Fitness, and Udder Conformation Traits}

Pearson correlations of sire breeding values for $\mathrm{CM}$ and SCC traits with official EBV of selected production, fitness, and udder conformation traits are shown in Table 6. Only sires with at least 50 daughters for CM and SCC traits were included. Correlations between breeding values are always an underestimation of genetic correlations, unless accuracies of estimated breeding values are close to one. Thus, these results should only be interpreted as general indications. As expected, antagonistic relationships were observed between milk production and CM traits, which is in agreement with previous studies (Heringstad et al., 2000).
Fast-milking cows were found to have a higher SCC, which was also reported by Rupp and Boichard (1999). In contrast, CM traits showed no or favorable associations with milking speed, confirming the findings of Rupp and Boichard (1999) and Sørensen et al. (2000). This indicates that easier flow of milk out of the udder is not necessarily associated with easier entry of pathogens and more CM treatments. As mentioned by Rupp and Boichard (1999), the association of fast milking with increased SCC could result from a more complete draining of the udder, because the last fraction of milk contains 3 to 10 times more cells than the foremilk. A more complete draining of the udder may also lead to a better elimination of pathogens and, thus, could result in a reduced risk of CM.

Muscling was positively correlated with all traits, which suggests that cows with more muscling are more robust and healthy. This is in agreement with previous studies, in which dairy form has been implicated as a potential indicator of disease susceptibility (e.g., Dechow et al., 2004).

In our study, significant positive correlations were found between CM traits and suspensory ligament, which means that cows with a strong ligament have less mastitis treatments. Udder depth and fore udder attachment were positively correlated with all traits, suggesting that cows with higher udders that are more tightly attached have less mastitis treatments and lower SCC. Similar associations between udder conformation and CM traits were shown in earlier studies (e.g., S $\varnothing$ rensen et al., 2000).

\section{Model Assumptions and Limitations}

Somatic cell score was defined as early lactation mean SCS and lactation mean SCS. Our results and previous results from Negussie et al. (2008) suggested that $\mathrm{CM}$ and SCS from the same interval may have a more similar genetic basis, and therefore, the application of test-day (longitudinal) models for SCS would be more appropriate. A longitudinal model can give a dynamic description of the genetic relationship between SCS and $\mathrm{CM}$ in the course of lactation. In the joint genetic evaluation of Austria and Germany, a longitudinal model is used for routine genetic evaluation of SCS. Therefore, the ability to combine information from test-day SCS with CM will be a subject for future studies.

This study was based on a small data set, so the genetic correlations could not be estimated very precisely. Most of the cows in the data set used to estimate genetic parameters were daughters of proven sires, which might have introduced some bias. Moreover, records from the first 5 lactations were analyzed together, and not all 
Table 6. Pearson correlations between EVB of sires with at least 50 daughters for clinical mastitis (CM) in lactation intervals 1 ( -10 to $50 \mathrm{~d}$ after calving), 2 (51 to $150 \mathrm{~d}$ after calving), and 3 ( -10 to $150 \mathrm{~d}$ after calving), early lactation SCS (ESCS), lactation mean SCS (LSCS), and subclinical mastitis (SM) based on Bayesian analyses and EBV for other traits routinely evaluated

\begin{tabular}{|c|c|c|c|c|c|c|}
\hline Item & $\begin{array}{c}\text { CM1 } \\
\text { (132 sires) }\end{array}$ & $\begin{array}{c}\text { CM2 } \\
\text { (119 sires) }\end{array}$ & $\begin{array}{c}\text { CM3 } \\
\text { (124 sires) }\end{array}$ & $\begin{array}{c}\text { ESCS } \\
\text { (138 sires) }\end{array}$ & $\begin{array}{c}\text { LSCS } \\
\text { (121 sires) }\end{array}$ & $\begin{array}{c}\text { SM } \\
\text { (121 sires) }\end{array}$ \\
\hline Milk kg & $-0.18^{*}$ & $-0.19^{*}$ & $-0.21^{*}$ & $-0.16 \dagger$ & 0.04 & 0.07 \\
\hline Fat $\%$ & 0.02 & 0.03 & 0.03 & 0.02 & -0.06 & -0.09 \\
\hline Longevity & 0.14 & 0.07 & 0.11 & $0.16 \dagger$ & $0.26^{* *}$ & $0.26^{* *}$ \\
\hline Persistency & 0.06 & $-0.17 \dagger$ & -0.05 & 0.03 & $0.28^{* *}$ & $0.19^{* *}$ \\
\hline Female fertility index & $0.19^{*}$ & 0.05 & 0.14 & $0.17 \dagger$ & 0.14 & $0.18 \dagger$ \\
\hline Fore udder attachment (loose-strong) & 0.16 & $0.24^{*}$ & 0.11 & 0.01 & 0.12 & 0.13 \\
\hline Suspensory ligament (weak-strong) & 0.13 & $0.20^{*}$ & $0.21^{*}$ & -0.02 & -0.07 & -0.02 \\
\hline Udder depth (deep-high) & 0.13 & $0.29^{* *}$ & $0.20 *$ & $0.17^{*}$ & $0.23^{*}$ & $0.28^{* *}$ \\
\hline Teat length (short-long) & -0.10 & -0.02 & -0.12 & -0.06 & -0.11 & $-0.18 \dagger$ \\
\hline Teat thickness (thin-thick) & -0.14 & -0.10 & $-0.15 \dagger$ & -0.07 & -0.10 & -0.14 \\
\hline Fore teat placement (outward-inward) & 0.03 & -0.06 & -0.01 & 0.00 & 0.04 & 0.08 \\
\hline Rear teat placement (outward-inward) & 0.10 & 0.00 & 0.08 & 0.10 & 0.11 & $0.18 \dagger$ \\
\hline
\end{tabular}

$\dagger P<0.10,{ }^{*} P<0.05,{ }^{* *} P<0.01$.

cows start with their first parity. Thus, it is important to reestimate these correlations based on a larger data set and to study CM in late parts of lactation.

\section{CONCLUSIONS}

Data from the Austrian health-monitoring project can be used for genetic evaluation of sires for udder health and thus for selection for improved resistance to mastitis. Heritability estimates of CM in early lactation ranged from 0.02 to 0.06 on the underlying liability scale, whereas heritability estimates of SCS traits and $\mathrm{SM}$ ranged from 0.09 to 0.13 . Genetic correlations between CM and ESCS, LSCS, or SM were between 0.64 and 0.77, which indicate that CM and SCC are not the same trait. The genetic correlation between SM and LSCS was almost 1. For selection of bulls, information on $\mathrm{CM}$ and SCC should be combined. Pearson correlations of sire breeding values for CM and SCC traits with udder conformation traits revealed that udder depth in particular may be useful as additional information to reduce both $\mathrm{CM}$ and SCC.

\section{ACKNOWLEDGMENTS}

The collaborative work of the project partners in Austria [Federation of Austrian Cattle Breeders including its member organizations of performance recording and breeding (Vienna, Austria), University of Natural Resources and Applied Life Sciences (Vienna, Austria), University of Veterinary Medicine (Vienna, Austria), Chamber of Agriculture (Vienna, Austria), Chamber of Veterinaries (Vienna, Austria), Coordination Office of Animal Health Organizations (St. Pölten, Austria)] to establish a "Health Monitoring System in Cattle" and all dairy farmers and veterinarians participating are gratefully acknowledged. This work was financed by the Austrian Federal Ministry of Agriculture, Forestry, Environment and Water Management (Vienna) and the Federation of Austrian Cattle Breeders (Vienna). Birgit Fuerst-Waltl was supported by the Austrian Science Foundation (Vienna; Elise-Richter Program V43-B12).

\section{REFERENCES}

Carlén, E., E. Strandberg, and A. Roth. 2004. Genetic parameters for clinical mastitis, somatic cell score, and production in the first three lactations of Swedish Holstein cows. J. Dairy Sci. 87:30623070 .

Dechow, C. D., G. W. Rogers, U. Sander-Nielsen, L. Kiel, T. J. Lawlor, J. S. Clay, A. E. Freeman, G. Abdel-Azim, A. Kuck, and S. Schnell. 2004. Correlations among body condition scores from various sources, dairy form, and cow health from the United States and Denmark. J. Dairy Sci. 87:3526-3533.

Egger-Danner, C., B. Fuerst-Waltl, W. Holzhacker, R. Janacek, J. Lederer, C. Litzllachner, C. Mader, M. Mayerhofer, J. Miesenberger, W. Obritzhauser, G. Schoder, and A. Wagner. 2007. Establishing a health monitoring for cattle in Austria: First experiences. Page 363 in Book of Abstracts of the 58th Annual Meeting of the EAAP, Dublin, Ireland. Wageningen Academic Publishers, Wageningen, the Netherlands.

Fuerst, C., J. Dodenhoff, R. Emmerling, D. Krogmeier, and E. Niebel. 2010. Zuchtwertschätzung beim Rind. http://www.zar.at/download/ZWS/ZWS.pdf Accessed May 6, 2010.

Gianola, D., and J. L. Foulley. 1983. Sire evaluation for ordered categorical data with a threshold model. Genet. Sel. Evol. 15:201224.

Heringstad, B., Y. M. Chang, D. Gianola, and G. Klemetsdal. 2004. Multivariate threshold model analysis of clinical mastitis in multiparous Norwegian dairy cattle. J. Dairy Sci. 87:3038-3046.

Heringstad, B., D. Gianola, Y. M. Chang, J. Ødegård, and G. Klemetsdal. 2006. Genetic associations between clinical mastitis 
and somatic cell score in early first-lactation cows. J. Dairy Sci. 89:2236-2244.

Heringstad, B., G. Klemetsdal, and J. Ruane. 2000. Selection for mastitis resistance in dairy cattle: A review with focus on the situation in the Nordic countries. Livest. Prod. Sci. 64:95-106.

Lund, M. S., J. Jensen, and P. H. Petersen. 1999. Estimation of genetic and phenotypic parameters for clinical mastitis, somatic cell production deviance, and protein yield in dairy cattle using Gibbs sampling. J. Dairy Sci. 82:1045-1051.

Madsen, P., and J. Jensen. 2008. An User's Guide to DMU. A Package for Analysing Multivariate Mixed Models, Version 6. Release 4.7. Danish Institute of Agricultural Sciences, Tjele, Denmark.

Negussie, E., I. Strandén, and E. A. Mäntysaari. 2006. Genetic analysis of clinical mastitis in different risk periods by linear and threshold models. Page 85 in Proc. 22nd Conf. Finnish Agric. Soc., Helsinki, Finland. The Scientific Agricultural Society of Finland, Helsinki.

Negussie, E., I. Strandén, and E. A. Mäntysaari. 2008. Genetic association of clinical mastitis with test-day somatic cell score and milk yield during first lactation of Finnish Ayrshire cows. J. Dairy Sci. 91:1189-1197.

Ødegård, J., B. Heringstad, and G. Klemetsdal. 2004. Short communication: Bivariate genetic analysis of clinical mastitis and somatic cell count in Norwegian dairy cattle. J. Dairy Sci. 87:3515-3517.

Raftery, A. E., and S. Lewis. 1992. How many iterations in the Gibbs sampler? Pages 763-774 in Bayesian Statistic 4. J. M. Bernando, J. O. Berger, A. P. Dawid, and A. F. M. Smith, eds. Oxford University Press, Oxford, UK.

Rupp, R., and D. Boichard. 1999. Genetic parameters for clinical mastitis, somatic cell score, production, udder type traits, and milking ease in first lactation Holsteins. J. Dairy Sci. 82:2198-2204.
Schukken, Y. H., D. J. Wilson, F. Welcome, L. Garrison-Tikofsky, and R. N. Gonzalez. 2003. Monitoring udder health and milk quality using somatic cell counts. Vet. Res. 34:579-596.

Shook, G. E., and M. M. Schutz. 1994. Selection on somatic cell score to improve resistance to mastitis in the United States. J. Dairy Sci. 77:648-658.

Smith, B. J. 2007. Boa: An R package for MCMC output convergence assessment and posterior inference. J. Stat. Softw. 21:1-37.

Sørensen, M. K., J. Jensen, and L. G. Christensen. 2000. Udder conformation and mastitis resistance in Danish first-lactation cows: Heritabilities, genetic and environmental correlations. Acta Agric. Scand. Anim. Sci. 50:72-82.

Sorensen, D., and D. Gianola. 2002. Likelihood, Bayesian and MCMC Methods in Quantitative Genetics. Springer-Verlag, New York, NY.

Svendsen, M., and B. Heringstad. 2006. Somatic cell count as an indicator of subclinical mastitis: Genetic parameters and correlations with clinical mastitis. Interbull Bull. 35:12-16.

ZuchtData. 2009. Jahresbericht 2009 - Zuchtprogramm und Leistungsprüfung. ZuchtData, Vienna. http://www.zar.at/article/articleview/16/1/306 Accessed May 10, 2010.

Zwald, N. R., K. A. Weigel, Y. M. Chang, R. D. Welper, and J. S. Clay. 2006. Genetic analysis of clinical mastitis data from onfarm management software using threshold models. J. Dairy Sci. $89: 330-336$. 